IRA-International Journal of Management \& Social Sciences

ISSN 2455-2267; Vol.10, Issue 03 (March 2018)

Pg. no. 119-124.

Institute of Research Advances

http://research-advances.org/index.php/RAJMSS

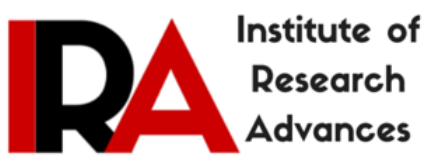

\title{
A Study of the Network Analysis in Enhancing the Managerial Efficiency of Dairy Co-Operative Personnels in Uttar Pradesh
}

\author{
Dr. Ashok Kumar \\ Associate Professor, Deptt. of Adult \& Continuing Education \& Extension, Jamia Millia Islamia, \\ New Delhi-110025, India.
}

Type of Review: Peer Reviewed.

DOI: http://dx.doi.org/10.21013/jmss.v10.n3.p4

How to cite this paper:
Kumar, A. (2018). A Study of the Network Analysis in Enhancing the Managerial Efficiency of Dairy
Co-Operative Personnels in Uttar Pradesh. IRA-International Journal of Management \& Social
Sciences (ISSN 2455-2267), 10(3), 119-124. doi:http://dx.doi.org/10.21013/jmss.v10.n3.p4

(C) Institute of Research Advances.

\section{$(\mathrm{cc}) \mathrm{BY}-\mathrm{NC}$}

This work is licensed under a Creative Commons Attribution-Non Commercial 4.0 International License subject to proper citation to the publication source of the work.

Disclaimer: The scholarly papers as reviewed and published by the Institute of Research Advances (IRA) are the views and opinions of their respective authors and are not the views or opinions of the IRA. The IRA disclaims of any harm or loss caused due to the published content to any party.

Institute of Research Advances is an institutional publisher member of Publishers Inter Linking Association Inc. (PILA-CrossRef), USA. The institute is an institutional signatory to the Budapest Open Access Initiative, Hungary advocating the open access of scientific and scholarly knowledge. The Institute is a registered content provider under Open Access Initiative Protocol for Metadata Harvesting (OAI-PMH).

The journal is indexed \& included in WorldCat Discovery Service (USA), CrossRef Metadata Search (USA), WorldCat (USA), OCLC (USA), Open J-Gate (India), EZB (Germany) Scilit (Switzerland), Airiti (China), Bielefeld Academic Search Engine (BASE) of Bielefeld University, Germany, PKP Index of Simon Fraser University, Canada. 


\begin{abstract}
The dairy organization represents a complex system is highly departmentalized and specialized at various levels, which has necessitated a great deal of co-ordination and interaction among its employees through an efficient organizational communication network. Net work analysis between management and employees at various levels of management plays an important role in achievement of the organizational effectiveness. The amount of upward communication was higher than downward communication as well as horizontal communication. The horizontal communication was also observed more than downward communication and hence, the efforts are required to attract the attention in this directionality the top management so that the management personnel could raise downward communication. Various types of communication messages i.e. informative, instructive, influencive, evaluative and counseling play a vital and indispensable role in management. The network analysis directly assist the management system in achieving the goals of the organization and also help in creating a congenial environment of better functioning by the incumbents in the organization.
\end{abstract}

Keywords: Network Analysis, Organizational Communication, Organizational Performance, Dairy Cooperatives and Managerial Efficiency.

\title{
INTRODUCTION
}

The importance of communication in organizational effectiveness has been widely recognized at theoretical and conceptual level. Organizational communication system has increasingly powerful determinants for the effectiveness of the organization and it may have an inflating effect on the ability of the organization to grow, to perform efficiently or to service. The dairy organization represents a complex system, which has necessitated a great deal of co-ordination and interaction among its employees through an efficient organizational communication network. Network analysis between management and employees at various levels of management plays an important role in achievement of the organizational effectiveness. The information and other specific messages i.e. informative, instructive, influencive, evaluative and counseling communicated to the members of the organization. These messages relayed in many directions. Some diffused downward others upward, still others in horizontal directions through various hierarchical levels of the organization, and play an important role in achieving the goals of the organization.

\section{RESEARCH METHODOLOGY}

Keeping in view the importance of the network analysis as effective determinants of the organizational communication, the present study was conducted under the aegis of Pradeshik Co-operative Dairy Federation Ltd. Uttar Pradesh. Under study sixteen districts of Western Uttar Pradesh were selected where Operation Flood Programme was in active operation for more than 15 years. The sampling design of the study was comprised of four hierarchical management levels viz. upper, middle, lower, and staff respectively. The composite sampling size of 64 includes upper level (16), middle level (16), and lower level (16) and staff level (16) respectively.

Net work analysis includes the Directionality and Types of messages. The information and other specific messages are communicated to the members of the organization. These messages are relayed in many directions. Some are diffused downward, others upward and still others in horizontal direction through various hierarchical level of the organization.

\section{DIRECTIONALITY OF MESSAGES}

The direction indicates the way in which the communication flows in an organization. The downward communication (Top to Bottom) refers the communication flowing down the line from Superior or Boss to the Subordinates. The upward Communication refers to communication of subordinates moving in an upward direction to superiors. Horizontal communication refers to the lateral communication occurring between peers/colleagues at the same hierarchical level.

The directionality of message was measured with a Directionality Index. The data for directionality index was collected against four to six items. The raw score of each item converted into standard scores by the following formula. 


\section{Raw Score Mean \\ Standard Score $=$}

\section{Standard Deviation}

The Standard score of all these items summed up to obtain the Index Value (Downward, Upward and Horizontal) for an individual.

\section{TYPES OF COMMUNICATION}

Under the types of communication, five types of messages viz. evaluative, influencive, informative, and instructive and counseling respectively were studied. The operational form of the above five types of communication were as follows:

(a) Evaluative Type: Thayer (1961) states that an administrator/ communicator is communicating evaluatively whenever he hears or read something which he evaluates or when he communicate his evaluations to others directly or in writing.

(b) Informative Type: Thayer (1961) states "all communication intended or not has the potential of being informative. Thus, we may say that as far as they are informative, all conceivable forms or devices of communication fall within the scope of being informative. We communicate informatively when we report, analyze, explain, describe, clarify, or ask or answer a question.

(c) Instructive Type: Thayer (1961) states that those who are hierarchically superior whether in family, business, military, civic or personal life often initiate communication not only for the purpose of informing their sub ordinates but often for the purpose of telling them what to do or how to do or directing them or of commanding their behavior in some way "orders, directives, requests, procedure even performance appraisal, all functions as command (and/ or control) messages."

(d) Influencive Type: Thayer (1961) states that influence usually employed to refer to the act of eliciting or channelizing a specific behavior on the part of the receiver, usually thought to be some action contrary to the receivers perceived best interests.

(e) Counseling Type: Counseling is defined as the communication in person to person situation on personal and / or official problems where one try to give receive all the possible alternatives/ solutions to the problems from which one can choose.

The type of communication was measured with the following procedures. The five statements represent five types of communication i.e. evaluative, informative, instructive, influencive and counseling were prepared. The response was recorded into four categories such as 'most frequently, frequently, least frequently and never.' For scoring, these categories were assigned an arbitrary weightage of 3,2,1 and 0 respectively. The separate index for each type of Communication was constructed from the data collected regarding the:

\section{Raw Score-Mean \\ Standard Score = \\ $\overline{\text { Standard Deviation }}$}

The obtained standard scores of all items were finally added up to denote separate index for different types of communication messages.

\section{FINDINGS AND DISCUSSION}

In the present study, all the three types of directionally of message was studied. The flow of communication among superiors, sub ordinates and colleagues at different levels of management of the organization had been depicted in Table -1 . 
Table-1: Direction of Communication Flow at Different Levels of Management

\begin{tabular}{|c|c|c|c|c|c|}
\hline \multirow{2}{*}{$\begin{array}{c}\text { Direction of } \\
\text { Communication }\end{array}$} & \multicolumn{4}{|c|}{ Levels of Management } & \multirow{2}{*}{$\begin{array}{c}\text { Mean } \\
\text { Score }\end{array}$} \\
\cline { 2 - 5 } & ULM & MLM & LLM & SLM & Sc. \\
\hline Upward & 2.08 & 2.40 & 2.21 & 1.97 & 2.16 \\
\hline Downward & 1.86 & 2.11 & 1.87 & 1.68 & 1.88 \\
\hline Horizontal & 1.97 & 2.33 & 2.21 & 2.01 & 2.13 \\
\hline
\end{tabular}

Sources: Authors Compilation Max. Score: 3.00; N=64

The data in the table-1 reveals that the amount of upward communication was higher than that of downward as well as horizontal communication at all the levels of management in the organization. Horizontal communication was also observed to be more in comparison to downward communication. The upward communication was observed to be almost equal to the horizontal communication at all the levels of management in the organization. This was in opposite with the findings of Thakur (1994) who reported more amount of downward communication than that of upward communication in SMB and PCDF organization. In upward communication, the extant of upward communication was higher at MLM than ULM. However, at LLM the extant of upward communication was found more as compared to ULM and SLM. The lowest extent of upward communication was observed at SLM, as they are on the position of subordinates for all the levels of management in the organization.

Downward communication was higher at MLM followed by LLM and SLM whereas it was observed lower extent at ULM. The extent of lower downward at ULM could not be said a good sign for the top management of the organization. It shows that there was filtration of information at the ULM as they do not want to pass each information received by them from the top authority of the organization.

It is also evident from the table that the horizontal communication found higher in comparison to downward communication at different levels of management. However, it was found lower in comparison to upward communication at different levels of management. Horizontal communication score found higher at MLM (2.33) followed by LLM (2.21),SLM (2.01) and ULM (1.79) respectively.

\section{TYPES OF COMMUNICATION}

In present study, the five types of communication messages viz. Evaluative, Informative, Instructive, Influencive and counseling respectively were studied. The findings have been in three sections viz. upward communication i.e. communication with superiors, downward communication i.e. communication with subordinates and horizontal communication with colleagues at different levels of management.

\section{Upward Communication (communication with Superiors)}

Different types of communication messages by the superiors at different levels of management are presented in Table-2.

Table-2: Types of Communication Messages Used by Superiors (Upward) at Different Levels of Management

\begin{tabular}{|c|c|c|c|c|c|}
\hline \multirow{2}{*}{$\begin{array}{l}\text { Types of } \\
\text { Messages }\end{array}$} & \multicolumn{4}{|c|}{ Levels of Management } & \multirow{2}{*}{$\begin{array}{l}\text { Mean } \\
\text { Score }\end{array}$} \\
\hline & ULM & MLM & LLM & SLM & \\
\hline Informative & 1.66 & 2.43 & 2.19 & 1.93 & 2.05 \\
\hline Instructive & 1.98 & 2.42 & 2.25 & 1.41 & 2.01 \\
\hline Evaluative & 2.09 & 2.34 & 2.23 & 1.72 & 2.09 \\
\hline Influencive & 2.42 & 2.46 & 2.31 & 2.52 & 2.43 \\
\hline Counseling & 2.25 & 2.34 & 2.09 & 2.28 & 2.24 \\
\hline
\end{tabular}

Sources: Authors Compilation Max. Score: 3.00; N=64

It is evident from the table-2 in Upward communication with superiors, Influencive types of messages (2.43) was found to be used maximum followed by Counseling type of messages (2.24), evaluative (2.09), Informative (2.05) and Instructive (2.01) respectively. The lowest score was obtained for the instructive type of messages 
(2.01). The evaluative type of messages (2.09) was observed more rather than informative and instructive type at different levels of management.

\section{Downward Communication (Communication with Sub-ordinates)}

Different types of communication messages by the sub ordinates i.e. downward communication at different levels of management is presented in Table -3 .

\section{Table-3: Types of Communication Messages Used by Subordinates (Downward) at Different Levels of} Management

\begin{tabular}{|c|c|c|c|c|c|}
\hline \multirow{2}{*}{$\begin{array}{l}\text { Types of } \\
\text { Messages }\end{array}$} & \multicolumn{4}{|c|}{ Levels of Management } & \multirow{2}{*}{$\begin{array}{l}\text { Mean } \\
\text { Score }\end{array}$} \\
\hline & ULM & MLM & LLM & SLM & \\
\hline Informative & 1.66 & 2.43 & 2.19 & 1.93 & 2.05 \\
\hline Instructive & 1.98 & 2.42 & 2.25 & 1.41 & 2.01 \\
\hline Evaluative & 2.09 & 2.34 & 2.23 & 1.72 & 2.09 \\
\hline Influencive & 2.42 & 2.46 & 2.31 & 2.52 & 2.43 \\
\hline Counseling & 2.25 & 2.34 & 2.09 & 2.28 & 2.24 \\
\hline
\end{tabular}

Sources: Authors Compilation Max. Score: 3.00; N=64

It is evident from the table-3 that the instructive type of message was found to be having maximum score at different level of management among various types of messages. Influencive messages (1.96) also obtained higher score followed by evaluative messages (1.83) followed by counseling messages (1.65). The lowest score was obtained for informative messages (1.30) among all the types of messages.

\section{Horizontal Communication (Communication with Colleagues / Peers):}

The types of Communication messages used by colleagues in horizontal communication has been given in Table-4

Table-4: Types of Communication Messages Used by Colleagues (Horizontal) at Different Levels of Management

\begin{tabular}{|c|c|c|c|c|c|}
\hline \multirow{2}{*}{$\begin{array}{c}\text { Types of } \\
\text { Messages }\end{array}$} & \multicolumn{4}{|c|}{ Levels of Management } & \multirow{2}{*}{$\begin{array}{c}\text { Mean } \\
\text { Score }\end{array}$} \\
\cline { 2 - 5 } & ULM & MLM & LLM & SLM & 2.04 \\
\hline Informative & 1.84 & 2.48 & 2.29 & 2.04 & 2.16 \\
\hline Instructive & 2.16 & 2.05 & 2.25 & 2.16 & 2.15 \\
\hline Evaluative & 1.97 & 2.47 & 2.11 & 1.83 & 2.09 \\
\hline Influencive & 2.00 & 2.28 & 2.27 & 2.13 & 2.17 \\
\hline Counseling & 1.88 & 2.37 & 2.12 & 1.91 & 2.07 \\
\hline
\end{tabular}

Sources: Authors Compilation Max. Score: 3.00; $\mathbf{N}=64$

It is evident from the tabvle-4 that influencive (2.17) message found to be maximum followed by informative (2.16) and instructive message (2.15). The evaluative message (2.09) and counseling message (2.07) obtained almost equally score at different levels of management by the management personnel. It is quite apparent from the table that almost each type of message communicated among colleagues at different levels of management. All the management personnel at different levels of management discussed with their colleagues without any hesitation. The influencive messages is most frequently used whereas informative and instructive messages frequently used followed by evaluative messages. Counseling types of messages (2.07) obtained the lowest score.

\section{CONCLUSION}

In communication system of dairy co-operative organization, network analysis which includes upward, downward and horizontal communication flow and various types of communication messages i.e. informative, instructive, influencive, evaluative and counseling play an vital and indispensable role in management. The network analysis directly assist the management system in achieving the goals of the organization and also help in creating a congenial environment of better functioning by the incumbents in the organization. The top 
management of dairy organization must recognize the importance of downward communication for guidance to the subordinates and feedback for messages sent upward by the management personnel. The suggestion system, grievance redressal system, counseling and solicitous of letters and open door policy from the top management must employ to improve the upward communication in the dairy co-operative organization.

\section{References}

[1] Ansari, M. A.(1990 ) Structural and Functional analysis of organizational communication in department of animal husbandry, Ph. D. thesis, I.V.R. I., Izzatnagar ( U. P.).

[2] Arya, H.P.S. and Jamal, Shagufta (1998) Communication effectiveness. Indian Journal of Extension Education, $34,3 \& 4,150$.

[3] Goldhaber,G. M. (1974) Organizational Communication. W. M. C. Brown Company Publishers, I.C.W.A. U.S.A.

[4] Thakur, A. K.(1994) A. Study on organizational communication in U.P. dairy co-operative set up. Ph.D. Thesis, (Unpublished) I.V.R.I., Izzatnagar .U.P., India.

[5] Thayer, L (1961) Administrative communication. Illinois; Richard, D. Irwin, Inc., U.S.A.

[6] Yadav, J. P. (1971) Communication pattern and upward communication in C. D. block agricultural administration. Ph.D. Thesis(Unpublished) I.A.R.I., New Delhi. 